\title{
TECNOLOGÍA EN LOGÍSTICA
}

Título: Tecnólogo (a) en Logística Jornada: Diurno, nocturno Código SNIES: 19603 Total créditos: 89 Modalidad: Presencial

\begin{tabular}{|c|c|c|}
\hline ESTUDIANTE & ASESOR & TITULO TRABAJO DE GRADO \\
\hline Calvera Ximena & Henry Ávila & $\begin{array}{l}\text { Estudio de factibilidad para la creación } \\
\text { de una empresa de tejidos }\end{array}$ \\
\hline $\begin{array}{l}\text { Jiménez León Esperanza } \\
\text { Naranjo Javier Francisco }\end{array}$ & Francisco Espitia & $\begin{array}{l}\text { Plan de negocio para una empresa } \\
\text { dedicada a la compra, adecuación y } \\
\text { venta de vehículos usados en Bogotá }\end{array}$ \\
\hline $\begin{array}{l}\text { López Poloche Sandra } \\
\text { Patricia } \\
\text { Ávila Ojeda María Angélica }\end{array}$ & Francisco Espitia & $\begin{array}{l}\text { Estudio de mercados para establecer } \\
\text { la factibilidad de la creación de una } \\
\text { empresa de lavado de carros móvil en } \\
\text { Mosquera - Cundinamarca. }\end{array}$ \\
\hline Gómez Caipa Nelson Andrés & Francisco Espitia & $\begin{array}{l}\text { Generación de estrategias de } \\
\text { mercadeo para un producto nuevo: } \\
\text { Café instantáneo saborizado }\end{array}$ \\
\hline Sotelo Claudia & Alexander Gutiérrez & $\begin{array}{l}\text { Elaboración e implementación del plan } \\
\text { de contingencia para la planta Gas Zipa } \\
\text { S.A. ESP }\end{array}$ \\
\hline Monroy Manrique Omar & Francisco Espitia & $\begin{array}{l}\text { Plan de negocios para una empresa } \\
\text { productora de quesos en el municipio } \\
\text { de Funza - Cundinamarca }\end{array}$ \\
\hline
\end{tabular}

